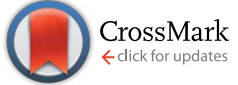

Cite this: RSC Adv., 2017, 7, 712

\title{
Effect of uniaxial pre-stretching on the microstructure and mechanical properties of poly [(ethylene oxide)-block-(amide-12)]-toughened poly(lactic acid) blend $\uparrow$
}

\author{
Yunjing Chen, ${ }^{\text {ab }}$ Lijing Han, ${ }^{* a}$ Zonglin $\mathrm{Li}^{\text {ac }}$ Junjun Kong, ${ }^{\text {ac }}$ Dandan $\mathrm{Wu}^{\text {ac }}$ \\ Zengwen $\mathrm{CaO}^{\mathrm{ab}}$ and Lisong Dong*a
}

\begin{abstract}
Highly oriented poly(lactic acid) (PLA)/20 wt\% poly[(ethylene oxide)-block-(amide-12)] (PEBA) blends were prepared via uniaxial pre-stretching technology at $60^{\circ} \mathrm{C}$ and $25^{\circ} \mathrm{C}$ to improve the mechanical properties of PLA. For the pre-stretching process at $60^{\circ} \mathrm{C}$, the tensile strength and modulus of the pre-stretched PLA/ PEBA blend dramatically increased with the increasing pre-stretching ratio (PSR), whereas the elongation at break for all the pre-stretched specimens was much higher than that of the neat PLA, suggesting that PEBA had an excellent toughening effect for PLA under uniaxial pre-stretching. The integrated morphological and structural analyses based on scanning electron microscopy (SEM) and wide-angle Xray diffraction (WAXD) indicated that the amorphous PLA phase started to develop orientation, mesophase, and even defective $\alpha$ crystal as parts of the key structure from the strengthening and stiffening effect by pre-stretching. Compared to the pre-stretching process at $60^{\circ} \mathrm{C}$, the strengthening and stiffening effect was abated for the blend pre-stretched at $25^{\circ} \mathrm{C}$. Moreover, the elongation at break significantly decreased with the increasing PSR, indicating that the pre-stretched blend in the hot prestretching process $\left(60^{\circ} \mathrm{C}\right)$ had more outstanding toughness than that in the cold pre-stretching process $\left(25^{\circ} \mathrm{C}\right)$. The possible reason for this is that the crack and pore defects formed during the pre-stretching process at $25{ }^{\circ} \mathrm{C}$ severely restricted the improvement of the mechanical properties of the blend. The thermal behavior of the pre-stretched blend tested by differential scanning calorimetry (DSC) showed that on increasing the PSR, glass transition temperature increased, cold-crystallization temperature decreased, and the degree of crystallinity increased, which further demonstrated the formation of the orientation or crystallization by pre-stretching.
\end{abstract}

Received 25th October 2016 Accepted 28th November 2016

DOI: 10.1039/c6ra25729a

www.rsc.org/advances

\section{Introduction}

Poly(lactic acid) or polylactide (PLA) is a thermoplastic aliphatic polyester derived from $100 \%$ renewable resources, such as corns and sugar beets. ${ }^{1}$ In the emerging bioplastics market, PLA has long been attractive due to its renowned merits of excellent biocompatibility and biodegradability, coupled with a high strength and modulus, and good processability. ${ }^{2,3}$ For these reasons, it offers great promise in a wide range of commodity applications, such as in biomedical materials ${ }^{4}$ and packaging applications. ${ }^{5,6}$

In spite of its favorable properties, the inherent brittleness of PLA, in essence, the relatively short chains, and rigid chain

${ }^{a}$ Key Laboratory of Polymer Ecomaterials, Changchun Institute of Applied Chemistry, Changchun 130022, China.E-mail: ljhan@ciac.ac.cn; dongls@ciac.ac.cn ${ }^{b}$ University of Science and Technology of China, Hefei, Anhui 230026, China 'University of Chinese Academy of Sciences, Beijing 10080, China

$\dagger$ Electronic supplementary information (ESI) available. See DOI: $10.1039 / \mathrm{c} 6 \mathrm{ra} 25729 \mathrm{a}$ backbone, limits most common plasticity mechanisms, therefore, prevents it from achieving a large ductile behavior, ${ }^{7}$ which greatly blocks its range of applications. In this context, the toughening of PLA has been studied for a long time and several approaches, including copolymerization, plasticization, and blending with flexible polymers, have been developed to modify PLA to introduce adequate ductility. In general, blending with elastomers is a more practical and economic way among these common methods. It has been reported that PLA was blended with various materials, such as rubbers, ${ }^{8}$ poly(butylene succinate) (PBS), ${ }^{9}$ poly( $\left(\varepsilon\right.$-caprolactone) (PCL) ${ }^{10}$ poly(butylene adipateco-terephthalate) (PBAT) ${ }^{11}$ and PEBA. ${ }^{12}$ However, most of the added polymers are derived from the non-renewable resources and do not exhibit biocompatibility, which clearly limits the environmental and biomedical applications of these blends. Moreover, the toughened PLA blends were found to have only a limited promotion of ductility, but with greatly reduced strength and stiffness. Hence, there is an imperative demand for the ideal combination of strength, stiffness, and ductility. 
It is known that the mechanical properties of the polymers can be significantly enhanced through the stretching processes. ${ }^{13-17}$ For PLA, Maspoch et al. ${ }^{18}$ and Wu et al. ${ }^{19}$ previously reported that the mechanical properties of drawn PLA films, including the modulus, tensile strength, and elongation at break, were simultaneously improved compared with the undrawn films. More recently, Jariyasakoolroj et al. ${ }^{20}$ clarified that the isotropically small crystalline lamellae formed in the biaxial stretching process was the key microstructure to obtain PLA with excellent performance (180 MPa tensile strength and $80 \%$ elongation at break). Moreover, Feng et al. ${ }^{21}$ and Zhao et al..$^{22}$ found that the tensile strength and modulus of the highly oriented poly(lactic acid) (PLA)/thermoplastic polyurethane (TPU) blend obtained by a solid hot stretching process were significantly improved, providing an effective method to strengthen the ductile PLA blend.

Naturally, this stimulated us to apply the stretching process for the improvement of strength and stiffness of a toughened PLA blend. In our previous study, PEBA, a biocompatible thermoplastic elastomer, which can be derived from renewable resources, including castor oil, and can be used as a toughening agent for brittle thermoplastic polymers due to its high impact resistance, ${ }^{23}$ was used as a toughening agent for PLA, and we successfully prepared a PLA blend with high toughness. ${ }^{12}$ In the present study, the PLA/PEBA blend, containing $20 \mathrm{wt} \%$ PEBA, was pre-stretched at the rubbery state (pre-stretching temperature $\left.T_{\mathrm{ps}}=60^{\circ} \mathrm{C}\right)$ as well as the glassy state $\left(T_{\mathrm{ps}}=25^{\circ} \mathrm{C}\right)$ for the purpose of further improving the mechanical properties of the blend. Moreover, the microstructure, crystallization behavior, and thermal properties were determined to establish a relationship between the microstructure and the mechanical properties. These new insights helped us to understand the microstructure of the drawn PLA/PEBA blend and its consequent mechanical properties, which enabled us to obtain a PLA/ PEBA blend with the desired mechanical properties by simply controlling the processing conditions, thereby allowing us to extend the application of the PLA/PEBA blend.

\section{Experimental}

\section{Materials}

The PLA used in the present study was the 4032D grade material from Natureworks LLC (USA) consisting of $98 \%$ L-lactic acid and $2 \%$ D-lactic acid. It exhibited a weight-average molecular weight of $207000 \mathrm{~g} \mathrm{~mol}^{-1}$ and a dispersity of 1.74 (gel permeation chromatography analysis, Waters 410 Gel permeation chromatograph with THF as the fluent (flow rate: $1 \mathrm{~mL} \mathrm{~min}^{-1}$ at 35 ${ }^{\circ} \mathrm{C}$ ) and polystyrene standards as the reference for the molecular weight calculations). The PEBA (Pebax 1074) with poly(ethylene oxide) (PEO) and polyamide-12 (PA12) blocks, available in granular form, was kindly supplied by Elf Atochem (France). It contained $55 \mathrm{wt} \%$ PEO blocks and $45 \mathrm{wt} \%$ PA12 blocks. ${ }^{24}$

\section{Preparation of the pre-stretched PLA/PEBA blend}

Sample preparation. First, the PLA and PEBA pellets were dried in a vacuum oven at $80^{\circ} \mathrm{C}$ for $12 \mathrm{~h}$. The specific PLA/PEBA blend containing $20 \mathrm{wt} \%$ PEBA was prepared using an internal mixer (XSS-300, Shanghai Kechuang Rubber Plastic Mechanical Equipment Co., Ltd., China) with a screw speed of $60 \mathrm{rpm}$ for a total mixing time of $5 \mathrm{~min}$ at $175{ }^{\circ} \mathrm{C}$. Moreover, neat PLA was subjected to the mixing treatment to have the same thermal history as that of the blend. After mixing, the sample was cut into small pieces for compression molding. Specimens intended for the pre-stretching process in the next step were prepared using a hot press with a wide dumbbell-shaped die at $180^{\circ} \mathrm{C}$ for 3 min, followed by a cold press at room temperature (RT) to form a PLA/PEBA blend with necks $25.0 \mathrm{~mm}$ long and crosssectional areas of $22.0 \mathrm{~mm} \times 1.0 \mathrm{~mm}$.

Pre-stretching experiments. To investigate the effect of the pre-stretching process on the mechanical properties of the drawn PLA/PEBA blend, pre-stretching experiments were carried out using a tensile-testing machine (Instron-1121, USA) equipped with a high-low temperature environmental chamber. The specimens were marked along the sample using ink to determine the local plastic strain, such as the pre-stretching ratio (PSR), where PSR $=\left(L / L_{\mathrm{O}}-1\right)$, and $L_{\mathrm{O}}$ and $L$ are the gauge lengths of the sample before and after deformation, respectively. The PLA/PEBA blends were pre-stretched with a stretching rate of $5 \mathrm{~mm} \mathrm{~min}{ }^{-1}$ and with various PSRs around the glass transition temperature $\left(60^{\circ} \mathrm{C}\right)$ and at room temperature $\left(25^{\circ} \mathrm{C}\right)$ for comparison. When the PLA/PEBA blends were pre-stretched at $60{ }^{\circ} \mathrm{C}$, specimens were heated to the drawing temperature and equilibrated at this temperature for $3 \mathrm{~min}$ before pre-stretching, whereas after deformation, the samples were cooled down to below $T_{\mathrm{g}}$ by air cooling before they were removed from the chamber. The preheating and cooling process were not required when the samples were pre-stretched at $25{ }^{\circ} \mathrm{C}$.

\section{Characterization}

Tensile testing. The static mechanical properties of neat PLA and the PLA/PEBA blends before and after the pre-stretching process were measured by a tensile-testing machine (Instron1121, USA) according to ISO 527-1:1993. The pre-stretched PLA/PEBA (ps-PLA/PEBA) samples were cut from the PLA/ PEBA blend after the pre-stretching experiments into the standard dumbbell-shaped specimens with necks $20.0 \mathrm{~mm}$ long and $4.0 \mathrm{~mm}$ wide. Note that the thickness of the ps-PLA/PEBA blends varied from $1.00 \mathrm{~mm}$ to $0.50 \mathrm{~mm}$ with the prestretching ratio (PSR). A schematic showing the preparation of the analysis specimens is provided in the Fig. S1 in the ESI. $\dagger$ Moreover, for comparison with the ps-PLA/PEBA samples, the undrawn PLA/PEBA blend was also cut from the previously compression-molded sheets into the standard dumbbell shape. The test was carried out along the pre-stretching direction with a crosshead speed of $5 \mathrm{~mm} \mathrm{~min}{ }^{-1}$ at room temperature $\left(25^{\circ} \mathrm{C}\right)$ in the tensile mode. At least five specimens were tested for each sample to obtain an average value.

SEM. The morphology of the PLA/PEBA blend before and after the pre-stretching process was observed using field emission scanning electron microscopy (FESEM; XL30 ESEM FEG, FEI Co., Eindhoven, The Netherlands) at an accelerating voltage 
of $10 \mathrm{kV}$. The samples were immersed in liquid nitrogen for about $3 \mathrm{~min}$, and then they broke off along the pre-stretching direction. The cryofractured surfaces of the samples before and after the pre-stretching process were coated with a thin layer of gold to acquire the SEM images; therefore, the dispersion of the PEBA particles in the PLA matrix and the orientation morphology of the blend after the pre-stretching process were obtained.

WAXD. Wide-angle X-ray diffraction (WAXD) was performed using a SAXSess $\mathrm{mc}^{2}$ (Anton Paar, Austria) instrument with monochromatic $\mathrm{Cu} \mathrm{K} \alpha$ radiation, of which the wavelength was $0.154 \mathrm{~nm}$. SAXSquant software system transferred the 2D diffraction image to the $1 \mathrm{D}$-curve with the background subtraction.

DSC. Thermal analysis was performed using a TA Instruments differential scanning calorimeter (DSC) Q20 with a Universal Analysis 2000. The sample weights were in the range of 5-8 mg. The heat enthalpy and temperature of the DSC were calibrated with standard indium. All the specimens were heated from $0{ }^{\circ} \mathrm{C}$ to $190{ }^{\circ} \mathrm{C}$ at a heating rate of $10{ }^{\circ} \mathrm{C} \mathrm{min}^{-1}$ under a nitrogen purge.

Apparent density. The apparent density of the PLA/PEBA samples $(\rho)$ before and after pre-stretching was estimated by the buoyancy method in water, and it was calculated by the following equation:

$$
\rho\left(\mathrm{g} \mathrm{cm}^{-3}\right)=\rho_{\mathrm{w}}\left(\mathrm{g} \mathrm{cm}^{-3}\right) \times\left[m /\left(m-m_{\mathrm{w}}\right)\right]
$$

where for the PLA/PEBA blend pre-stretched or not, $m$ is the mass in air, $m_{\mathrm{w}}$ is the mass in water, and $\rho_{\mathrm{w}}$ is the density of the water at the test temperature.

\section{Results}

\section{Mechanical properties of the ps-PLA/PEBA blend}

Fig. 1 shows the tensile stress-strain curves of neat PLA, the undrawn PLA/PEBA blend, and the ps-PLA/PEBA blend obtained at $60^{\circ} \mathrm{C}$ and $25^{\circ} \mathrm{C}$. The corresponding data for the mechanical properties are listed in Table 1 . Generally, neat PLA was rigid and brittle with a strength at break $\sim 65 \mathrm{MPa}$, a Young's modulus $\sim 1.7 \mathrm{GPa}$, and $\sim 5 \%$ elongation at break. In addition, no distinct yield point appeared before failure upon the tensile load. However, the undrawn PLA/PEBA blend exhibited a long, cold draw plateau with an obvious yield and neck formation. More importantly, the addition of $20 \mathrm{wt} \%$ PEBA significantly improved the toughness of PLA but weakened the strength and stiffness, which could be attributed to the toughening effect of PEBA on PLA. When the PLA/PEBA blends were pre-stretched at $60{ }^{\circ} \mathrm{C}$ with various PSRs, their tensile stress-strain curves showed a typical deformation behavior of the polymers, including yielding, neck growth, and strain hardening. Moreover, the neck growth behavior became much weaker with the increasing PSR, and it was then too faint to be observed when the PSR reached 2.0. As expected, the strength and stiffness of the ps-PLA/PEBA blend were obviously enhanced and the toughness still remained at a high level, as shown in Fig. 1 and Table 1. In detail, the strength at yielding and break, as well as
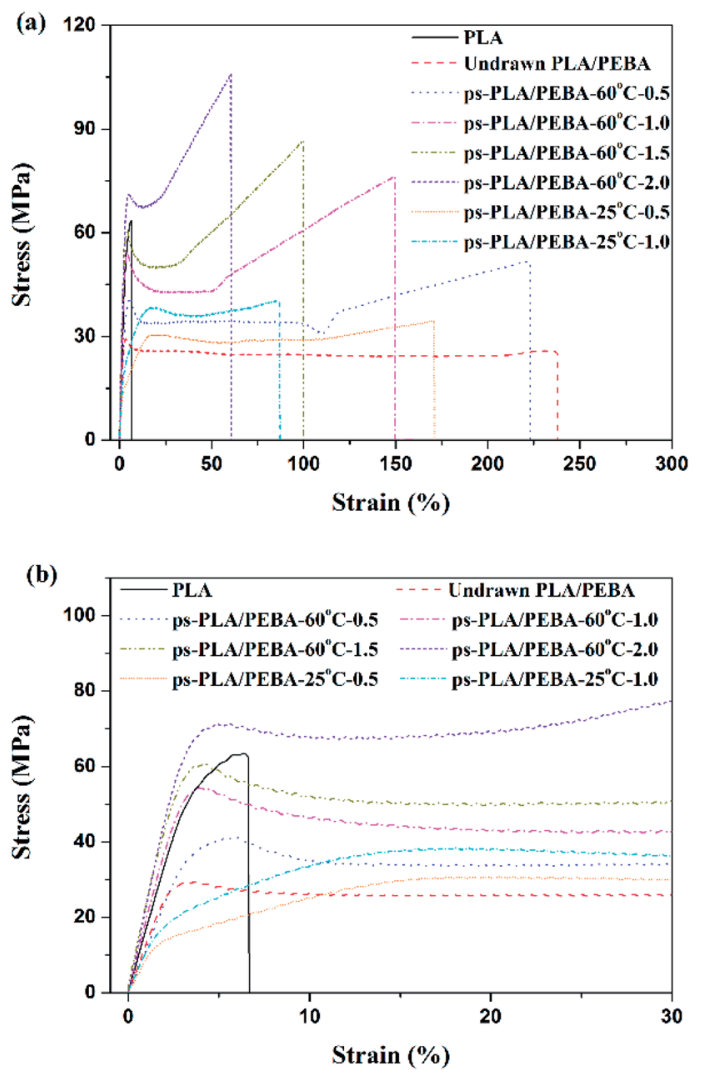

Fig. 1 (a) Tensile stress-strain curves of neat PLA and the PLA/PEBA blend before and after the pre-stretching process at $60{ }^{\circ} \mathrm{C}$ and $25^{\circ} \mathrm{C}$ with various PSRs; (b) further details of the tensile stress at the low strain of (a).

the modulus increased from 34.4 MPa, 28.4 MPa, and 1279 MPa for the undrawn blend to $68.8 \mathrm{MPa}, 100 \mathrm{MPa}$, and $2370 \mathrm{MPa}$ for the pre-stretched blend when the PSR was up to 2.0, which increased by $100 \%, 252 \%$, and $85 \%$, respectively. However, the elongation at break decreased from the maximum 229-60\%, which was still greater than that of neat PLA. These results revealed that for the flexible PLA/PEBA blend, the larger the PSR, the more distinct the strengthening and stiffening effect. In addition, the toughness was still maintained at a high level, even for the super-reinforced ps-PLA/PEBA blend.

The pre-stretching process was also performed at $25^{\circ} \mathrm{C}$ to further explore the influence of $T_{\mathrm{ps}}$ on the mechanical properties of the PLA/PEBA blend. It can be observed that the modulus and the strength at yielding and at break of the ps-PLA/PEBA blend pre-stretched at $25{ }^{\circ} \mathrm{C}$ increased with the increasing PSR, however, the increasing range was smaller than that of the samples pre-stretched at $60{ }^{\circ} \mathrm{C}$, as depicted in Table 1 . Note that the elongation at break of the ps-PLA/PEBA blend dramatically decreased to $62 \%$ when the PSR was only 1.0 , which was close to that of the samples pre-stretched at $60{ }^{\circ} \mathrm{C}$ with $\mathrm{PSR}=2.0$, indicating that the ps-PLA/PEBA blend in the hot pre-stretching process $\left(T_{\mathrm{ps}}=60^{\circ} \mathrm{C}\right)$ had more outstanding toughness than that from the cold pre-stretching process $\left(T_{\mathrm{ps}}=25^{\circ} \mathrm{C}\right)$. The total elongation $\left(\varepsilon_{\mathrm{t}}\right)$ of the pre-stretched blends, combining the elongation results both of the pre-stretching process and the 
Table 1 Mechanical properties of the PLA/PEBA blend before and after pre-stretching at $60{ }^{\circ} \mathrm{C}$ and $25^{\circ} \mathrm{C}$ with various PSRs

\begin{tabular}{|c|c|c|c|c|c|c|}
\hline Sample & PSR & $\begin{array}{l}\text { Strength at yielding } \\
(\mathrm{MPa})\end{array}$ & $\begin{array}{l}\text { Strength at } \\
\text { break (MPa) }\end{array}$ & Modulus (MPa) & $\begin{array}{l}\text { Elongation at } \\
\text { break (\%) }\end{array}$ & $\begin{array}{l}\text { Total elongation } \\
(\%)\end{array}$ \\
\hline Undrawn PLA/PEBA & - & $31.8 \pm 0.9$ & $26.8 \pm 1.2$ & $1279 \pm 34$ & $229 \pm 20$ & $229 \pm 20$ \\
\hline \multirow[t]{4}{*}{ Ps-PLA/PEBA- $60{ }^{\circ} \mathrm{C}$} & 0.5 & $41.8 \pm 1.0$ & $53.6 \pm 1.1$ & $1196 \pm 154$ & $225 \pm 5$ & $388 \pm 5$ \\
\hline & 1.0 & $53.4 \pm 0.9$ & $76.7 \pm 0.8$ & $1878 \pm 61$ & $148 \pm 2$ & $396 \pm 2$ \\
\hline & 1.5 & $57.5 \pm 1.4$ & $83.8 \pm 2.5$ & $2135 \pm 170$ & $95 \pm 6$ & $388 \pm 6$ \\
\hline & 2.0 & $68.8 \pm 2.2$ & $100.0 \pm 2.0$ & $2370 \pm 145$ & $60 \pm 1$ & $380 \pm 1$ \\
\hline \multirow[t]{2}{*}{ Ps-PLA/PEBA-25 ${ }^{\circ} \mathrm{C}$} & 0.5 & $31.3 \pm 0.8$ & $31.2 \pm 3.0$ & $766 \pm 192$ & $123 \pm 47$ & $234 \pm 47$ \\
\hline & 1.0 & $37.8 \pm 0.4$ & $37.3 \pm 3.0$ & $1075 \pm 5$ & $62 \pm 26$ & $224 \pm 26$ \\
\hline
\end{tabular}

tensile test, is listed in Table 1, such that we can give a comprehensive assessment of the toughness of the materials. Furthermore, it is defined as follows:

$$
\varepsilon_{\mathrm{t}}=\left[(1+\operatorname{PSR})\left(1+\varepsilon_{\mathrm{b}} / 100\right)-1\right] \times 100
$$

where $\varepsilon_{\mathrm{b}}$ is the elongation at break for the tensile test. According to eqn (2), there is a quantitative relationship between the PSR of the pre-stretching process and elongation at break of the tensile test:

$$
\varepsilon_{\mathrm{b}}=\left(100+\varepsilon_{\mathrm{t}}\right) /(1+\mathrm{PSR})-100
$$

Fig. 2 shows the variation of the elongation at break with the PSR and the fitting data for them at $60{ }^{\circ} \mathrm{C}$ and $25{ }^{\circ} \mathrm{C}$. This shows that the elongation at break is proportional to $1 /(1+$ PSR $)$ for all the samples, and the whole toughness of the materials prestretched at different temperatures could be determined from the slope of the linear relationship, for example, (514-100\%), i.e., $414 \%$ for $60{ }^{\circ} \mathrm{C}$ and (330-100\%), i.e., 330\% for $25^{\circ} \mathrm{C}$, which is approximate to the total elongation listed in Table 1 . Therefore, this linearity might be helpful to prepare a desire PLA/PEBA blend with high strength and stiffness, as well as good toughness. In summary, hot pre-stretching at $60{ }^{\circ} \mathrm{C}$ is an effective method to improve the mechanical properties of the PLA/PEBA blend.

\section{Morphology of the ps-PLA/PEBA blend}

The cross-sectional morphology of the PLA/PEBA blend prestretched with varying PSRs at $60{ }^{\circ} \mathrm{C}$ and $25{ }^{\circ} \mathrm{C}$ are shown in

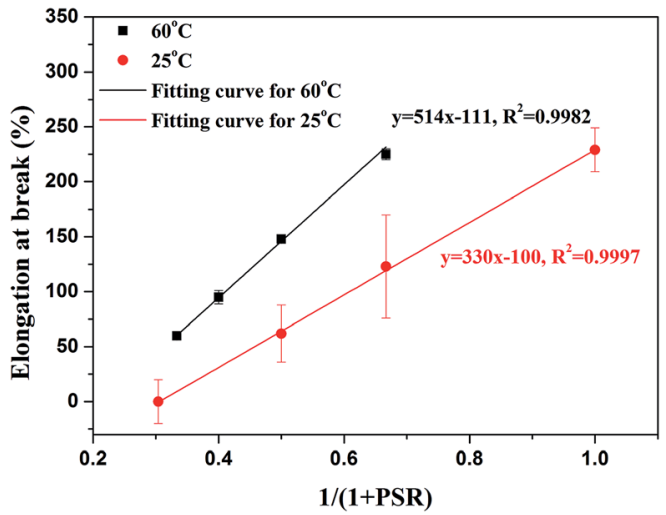

Fig. 2 Elongation at break of the ps-PLA/PEBA blend pre-stretched at different temperatures as a function of $1 /(1+P S R)$.
Fig. 3. It can be seen that all the PLA/PEBA blends showed a clear, phase-separated morphology, which indicated that the blends were immiscible. The immiscibility of the PLA/PEBA blend could also be demonstrated by two distinct glass transitions in the tan $\delta$ curves, one for PEBA at approximately $-45{ }^{\circ} \mathrm{C}$ and the other for PLA at approximately $68^{\circ} \mathrm{C}$, which was the same as that for the neat sample (see Fig. S2 in ESI $\dagger$ ). However, the sub-micron and micron dispersion of the PEBA minor phase in the PLA matrix revealed the good compatibility of the PLA/ PEBA immiscible system, which may be responsible for the significant increase in the toughness of PLA. ${ }^{\mathbf{1 2 , 2 5}}$ From Fig. 3(a), the undrawn PLA/PEBA blend did not show any specific orientation. However, when the blends were pre-stretched at $60{ }^{\circ} \mathrm{C}$,
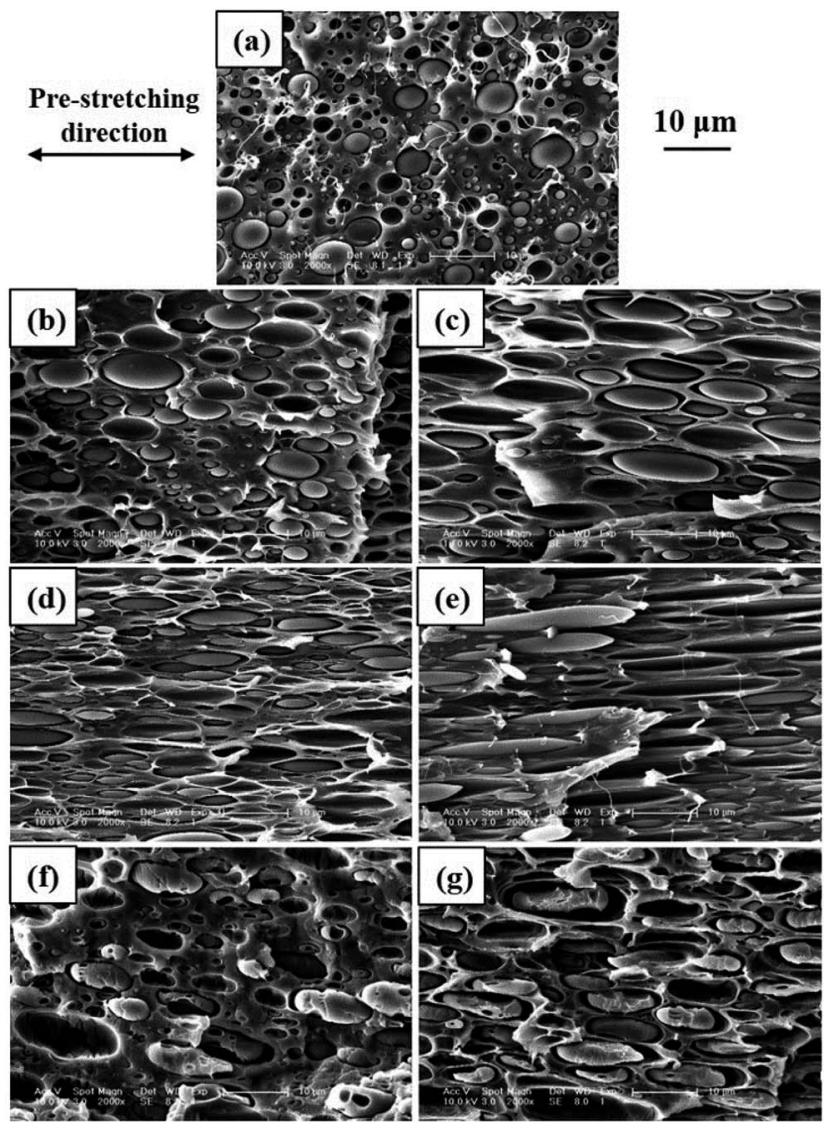

Fig. 3 SEM images of cross-sections for (a) undrawn PLA/PEBA blend and ps-PLA/PEBA blends pre-stretched at $60^{\circ} \mathrm{C}$ with a PSR of: (b) 0.5 , (c) 1.0, (d) 1.5 , and (e) 2.0 , and at $25^{\circ} \mathrm{C}$ with various PSRs of: (f) 0.5 and (g) 1.0 . 
the longitudinal fracture surfaces of them exhibited uniform orientation structures parallel to the pre-stretching direction, including the oriented PLA matrix and elongated PEBA minor phase. On increasing the PSR, the orientation structures were more evident. As already reported, it is the high degree of orientation that contributes to the significantly improved tensile strength and modulus of the blends. ${ }^{18,19,21,22}$ For the blends pre-stretched at $25{ }^{\circ} \mathrm{C}$, the orientation structures also gradually developed with the increasing PSR. However, a debonding process took place at the same time, leading to an obvious phase-separation, which was faint at $T_{\mathrm{ps}}=60^{\circ} \mathrm{C}$. Note that that the crack and pore defects were discovered in the PLA matrix and PEBA phase resulting from the weak deformation ability of PLA and PEBA in the glassy state, as shown in Fig. 3(f) and $(\mathrm{g})$. This phenomenon will be further confirmed by the density analysis in the following section. Just because of the obvious phase-separation and the crack and pore defects, the blends pre-stretched at $25{ }^{\circ} \mathrm{C}$ showed a decreased tensile strength, modulus, and elongation at break compared to those of the blends pre-stretched at $60{ }^{\circ} \mathrm{C}$ with the same PSR.

\section{WAXD of the ps-PLA/PEBA blend}

To understand the structure evolution with the dramatic property changes of the PLA/PEBA blend, WAXD measurements were performed on these pre-stretched PLA/PEBA blends. Fig. 4 displays the 2D-WAXD patterns of the undrawn PLA/PEBA blend

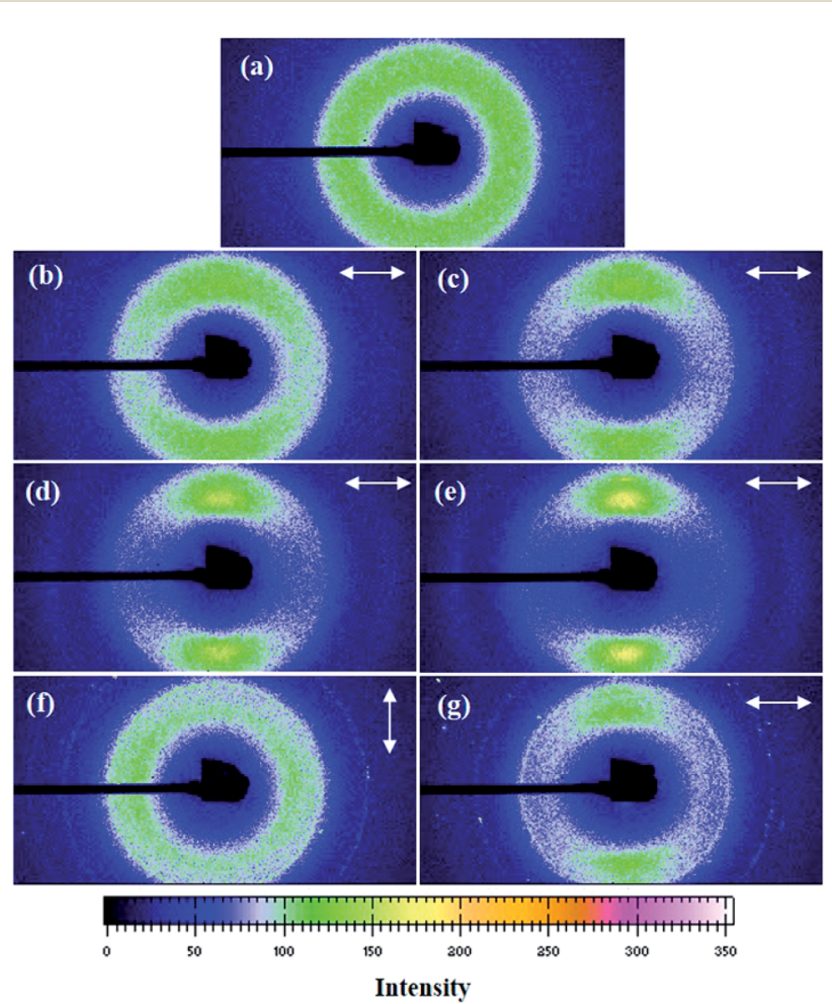

Fig. 4 2D-WAXD patterns of (a) undrawn PLA/PEBA and ps-PLA/PEBA blends pre-stretched at $60^{\circ} \mathrm{C}$ with PSR is (b) 0.5 , (c) 1.0 , (d) 1.5 , and (e) 2.0, and at $25{ }^{\circ} \mathrm{C}$ with various PSRs of (f) 0.5 and (g) 1.0 (the prestretching direction is along the arrow). and the ps-PLA/PEBA blend pre-stretched with various PSRs, whereas the corresponding WAXD intensity profiles are shown in Fig. 5. It can be seen from Fig. 4(a) that the diffuse halo of the 2D-WAXD pattern is isotropic, indicating that the undrawn PLA/ PEBA blend was nearly amorphous and there was no oriented structure in it.

When the blends were pre-stretched at $60{ }^{\circ} \mathrm{C}$, an obvious intensity increase of the inner broad diffraction on the meridian and a concomitant intensity decrease on the equator gradually developed with the increasing PSR, suggesting that the amorphous phase was oriented step by step during the pre-stretching process. Note that the diffraction halo of the amorphous phase gradually developed into a pair of broad diffraction arcs on the meridional position at a PSR of around 1.0, which was the sign of the appearance of the mesophase with an intermediate ordering state between the crystalline state and the amorphous state, as already reported by Stoclet et $a .^{26}$ and Wang et al. ${ }^{27}$ On further increasing the PSR, a pair of broad arcs were steadily concentrated in the meridional direction and no Debye-Scherrer rings for the crystals were observed. However, a pair of weak diffraction spots appeared among the diffraction arcs of the mesophase in the meridional direction at PSR $=1.5$, which suggested that the diffraction due to the oriented incomplete crystals of $\alpha$-form were buried or hidden in the broad diffraction. When the PSR was up to 2.0, the diffraction of the spots was more intense and a pair of short and narrow arcs appeared outside the spots, indicating that the degree of crystallinity increased with the increasing PSR.
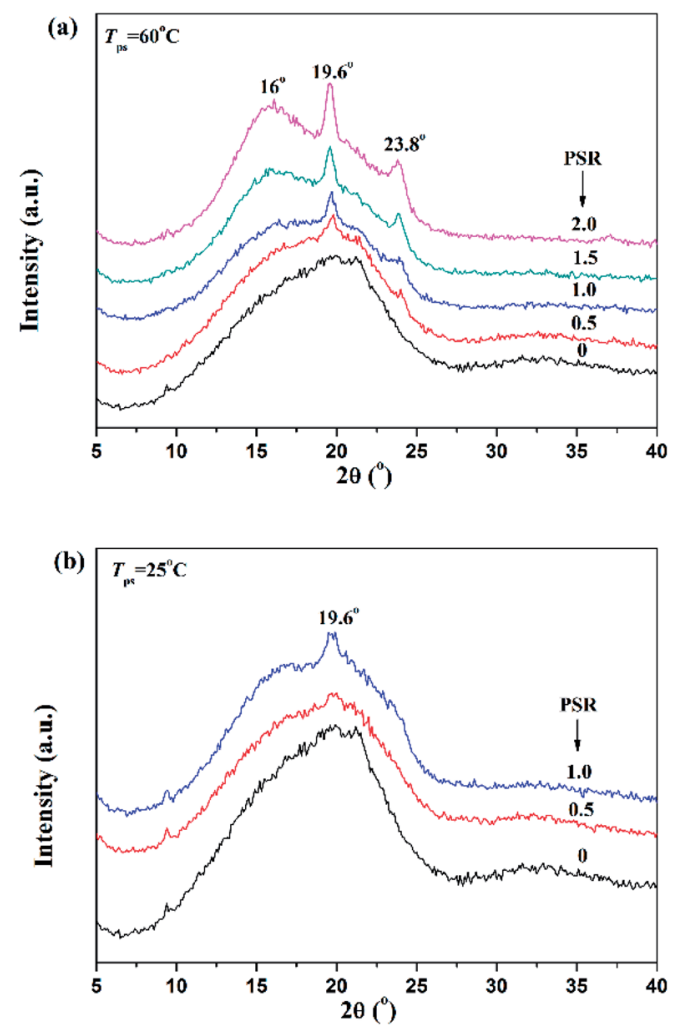

Fig. 5 WAXD intensity profiles of the PLA/PEBA blend before and after the pre-stretching process with various PSRs at (a) $60^{\circ} \mathrm{C}$ and (b) $25^{\circ} \mathrm{C}$. 
Detailed information about the crystals could be obtained from the intensity profiles of the WAXD plots presented in Fig. 5(a). It can be seen that the undrawn PLA/PEBA blend showed a broad diffraction pattern, which was assigned to the amorphous phase, with two weak diffraction peaks at around $19.6^{\circ}$ and $21.3^{\circ}$, which are characteristic of the defective $\alpha$-form crystal ( $\alpha^{\prime}$-form crystal) in PLA and the crystalline PA phases in PEBA, respectively. ${ }^{28,29}$ In addition, the weak diffraction peak at $21.3^{\circ}$ was negligible after the pre-stretching process. For the psPLA/PEBA blend, a broad amorphous phase with two sharp diffraction peaks at $19.6^{\circ}$ and $23.8^{\circ}$ was observed. These peaks are ascribed to the incomplete crystal of the $\alpha$-form of PLA. ${ }^{28,30}$ With an increase in PSR, the intensity of the diffraction peaks for the defective $\alpha$-form crystal was enhanced, whereas the amorphous phase was decreased stepwise. Furthermore, a slight and broad diffraction peak at $16^{\circ}$, belonging to the mesophase, appeared when the PSR was around 1.0, which could be further confirmed by the occurrence of the scattering contribution at $2 \theta=16.2^{\circ}$ obtained from fitting the data (Jade 6.0 peak fitting software), following the example of Stoclet et al. (see Fig. S3 in the ESI $\dagger$ ). However, for the same PSR, a higher orientation in the amorphous phase was achieved at a lower $T_{\mathrm{ps}}$ $\left(25{ }^{\circ} \mathrm{C}\right)$ due to the slower chain relaxation. ${ }^{30}$ Therefore, the strain-induced crystals were more easy to form, which could be evidenced by the more concentrated broad arcs of the amorphous phase and the weak Debye-Scherrer ring in Fig. 4(g). In summary, these results suggested that the ordered domain grew with the increasing PSR and the orientation structures gradually developed into a mesophase and even defective $\alpha$-form crystal, which were the key factors for the improved strength and stiffness of the ps-PLA/PEBA blend. ${ }^{20,31,32}$

\section{Thermal behavior of the ps-PLA/PEBA blend}

The pre-stretching process led to remarkable changes in the mechanical properties and microstructure of the PLA/PEBA blend, which were directly reflected in the thermal behavior. DSC measurements were performed to evaluate the influence of the pre-stretching process on the thermal behavior of the PLA/ PEBA blend. The DSC thermograms of the undrawn and the ps-PLA/PEBA blend drawn at $60{ }^{\circ} \mathrm{C}$ and $25{ }^{\circ} \mathrm{C}$ are shown in Fig. 6, and the corresponding data are summarized in Table 2. The undrawn blend exhibited a glass transition at around $57.4{ }^{\circ} \mathrm{C}$ for the PLA matrix. Subsequently, a broad exothermic peak of cold crystallization within the temperature range from $85{ }^{\circ} \mathrm{C}$ to $140{ }^{\circ} \mathrm{C}$ appeared. Afterwards, double melting peaks were found while heating, which were caused by a meltingrecrystallization process of the defective crystals grown as a result of cold-crystallization. ${ }^{33}$ Furthermore, the crystallinity $\left(\chi_{\mathrm{c}}\right)$ of the undrawn sample was as small as $2.4 \%$, indicating that the precursor was nearly amorphous.

Fig. 6(a) shows the DSC thermograms of the blend prestretched at $60{ }^{\circ} \mathrm{C}$. On increasing the PSR, the glass transition temperature $\left(T_{\mathrm{g}}\right)$ of the ps-PLA/PEBA blend moved to a higher temperature as a consequence of an increase in the chain segment orientation. Note that a sharp endotherm just above the glass transition was observed at PSR $=1.0$, and this became
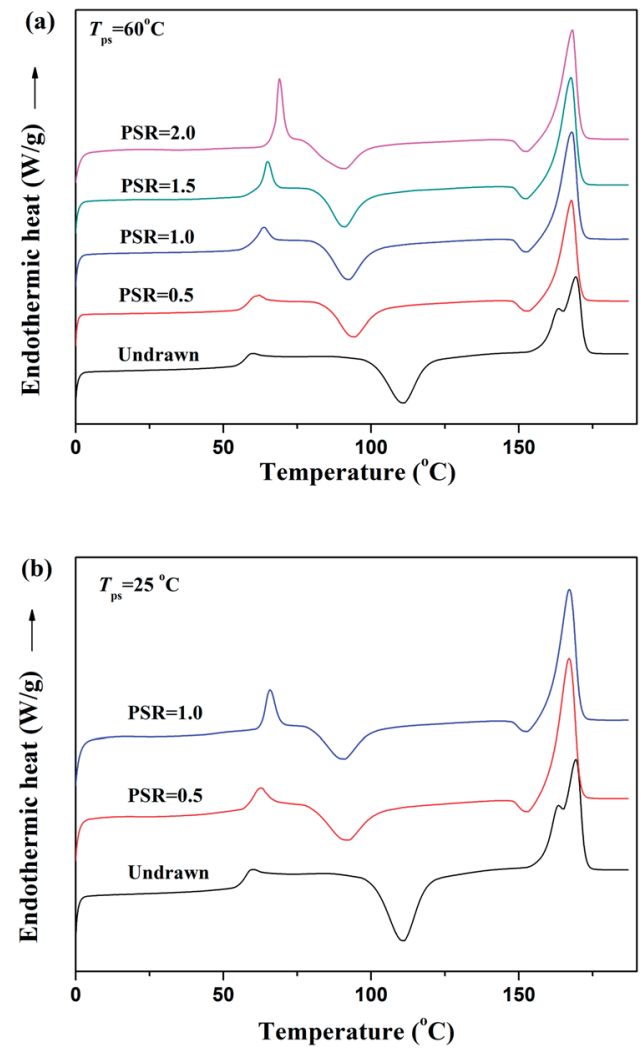

Fig. 6 The first heating traces of the DSC thermograms for the PLA/ PEBA blend before and after the pre-stretching process at (a) $60{ }^{\circ} \mathrm{C}$ and (b) $25{ }^{\circ} \mathrm{C}$ with various PSRs.

more intense and appeared at higher temperatures on increasing the PSR. This post- $T_{\mathrm{g}}$ endothermic peak has been ascribed to the melting of the mesophase with certain molecular ordering and thus its peak temperature represents the thermal stability of the mesophase. ${ }^{26}$ This is also a hint of the appearance of the mesophase at PSR $=1.0$, which is in agreement with the conclusions obtained from the WAXD measurements in the preceding section. The cold-crystallization temperature $\left(T_{\mathrm{cc}}\right)$ moved to a lower temperature and its peak area became smaller after the pre-stretching process. This underlined the crystallization kinetics improvement due to the increase in the chain orientation. The double melting peak shifted to a single melting peak with the remaining $T_{\mathrm{m} 2}$ being at $\sim 168{ }^{\circ} \mathrm{C}$, accompanied by a small exothermic peak for the transition of $\alpha^{\prime}$ to $\alpha$ crystal just before the melting peak. ${ }^{26,34,35}$ The DSC thermograms of PLA pre-stretched at $25^{\circ} \mathrm{C}$ showed a similar evolution from the increased $T_{\mathrm{g}}$ and decreased $T_{\mathrm{cc}}$, however, the amplitude of the variations were more obvious, indicating that the molecular chains were more ordered at lower $T_{\mathrm{ps}}$ with the same PSR. Hence, the strain-induced crystals were more easily formed, as proven by the higher $\chi_{\mathrm{c}}$ compared to that at $60{ }^{\circ} \mathrm{C}$. However, it has already been clarified that a mesomorphic ordering of the chains gradually builds up on increasing the strain only when $T_{\mathrm{ps}}<75{ }^{\circ} \mathrm{C} .{ }^{28}$ Herein, the formation of the strain-induced crystals may result from the nucleation of the toughening agent (PEBA) for PLA. ${ }^{36}$ 
Table 2 Thermal and crystalline properties of the undrawn and pre-stretched PLA/PEBA blends obtained from the first heating traces at a rate of $10{ }^{\circ} \mathrm{C} \min ^{-1}$

\begin{tabular}{llllllll}
\hline Sample & PSR & $T_{\mathrm{g}}\left({ }^{\circ} \mathrm{C}\right)$ & $T_{\mathrm{cc}}{ }^{a}\left({ }^{\circ} \mathrm{C}\right)$ & $\Delta H_{\mathrm{cc}}{ }^{a}\left(\mathrm{~J} \mathrm{~g}^{-1}\right)$ & $T_{\mathrm{m} 1}\left({ }^{\circ} \mathrm{C}\right)$ & $T_{\mathrm{m} 2}\left({ }^{\circ} \mathrm{C}\right)$ & $\Delta H_{\mathrm{m}}\left(\mathrm{J} \mathrm{g}{ }^{-1}\right)$ \\
\hline Undrawn PLA/PEBA & - & 57.4 & 109.2 & 26.6 & 162.9 & 169.2 & 28.4 \\
Ps-PLA/PEBA-60 ${ }^{\circ} \mathrm{C}$ & 0.5 & 58.8 & 94.4 & 26.3 & - & 167.8 & 32.2 \\
& 1.0 & 62.3 & 92.4 & 28.3 & - & 167.9 & 36.0 \\
& 1.5 & 64.2 & 91.0 & 26.2 & - & 167.7 & 34.8 \\
Ps-PLA/PEBA-25 ${ }^{\circ} \mathrm{C}$ & 2.0 & 68.1 & 91.2 & 24.8 & - & 168.2 & 34.7 \\
& 0.5 & 60.5 & 92.3 & 24.6 & - & 167.0 & 33.6 \\
& 1.0 & 64.4 & 91.0 & 18.6 & 167.1 & 31.4
\end{tabular}

${ }^{a}$ Cold crystallization at a heating rate of $10{ }^{\circ} \mathrm{C} \min ^{-1}$ (first heating). ${ }^{b}$ Degree of crystallinity, $\chi_{\mathrm{c}}(\%)=100 \times\left(\Delta H_{\mathrm{m}}-\Delta H_{\mathrm{cc}}\right) / \Delta H_{\mathrm{m}}^{\circ}(1-\phi)$, where $\Delta H_{\mathrm{cc}}$ and $\Delta H_{\mathrm{m}}$ are not corrected for the content of PLA in the blend, and $\Delta H_{\mathrm{m}}^{\circ}=93 \mathrm{~J} \mathrm{~g}^{-1}$.

\section{Discussion}

Previous results declared that the orientation or strain-induced crystals resulting from the drawing process are the key structures for enhancing the mechanical properties, such as tensile strength and modulus of the polymers. ${ }^{18-22,31,32}$ Herein, the prestretching process performed at different temperatures resulted in distinct mechanical changes of the PLA/PEBA blend. When the pre-stretching process was performed at $60{ }^{\circ} \mathrm{C}$, the ps-PLA/ PEBA blend exhibited an oriented PLA matrix and an elongated PEBA phase. On increasing the PSR, the orientation of an amorphous phase gradually developed, and then the mesophase and the strain-induced crystals were fabricated, as confirmed by the more and more concentrated diffraction arcs in the 2D-WAXD patterns and from the intense diffraction peak in the WAXD profiles. This consequence could also be deduced from the DSC thermograms by the increased $T_{\mathrm{g}}$, intensified post- $T_{\mathrm{g}}$ endothermic peak, decreased $T_{\mathrm{cc}}$, and the weakened cold-crystallization peak. It is speculated that the orientation in the amorphous phase and the strain-induced mesophase as well as the crystals are the critical factors for strengthening and stiffening the toughened-PLA. In detail, the molecular chains orient in the drawing direction after the pre-stretching process and the strength of the covalent bond in the molecular chain is far higher than that of the van der Waals forces; thus, it would need more tensile strength to snap the materials. Moreover, the

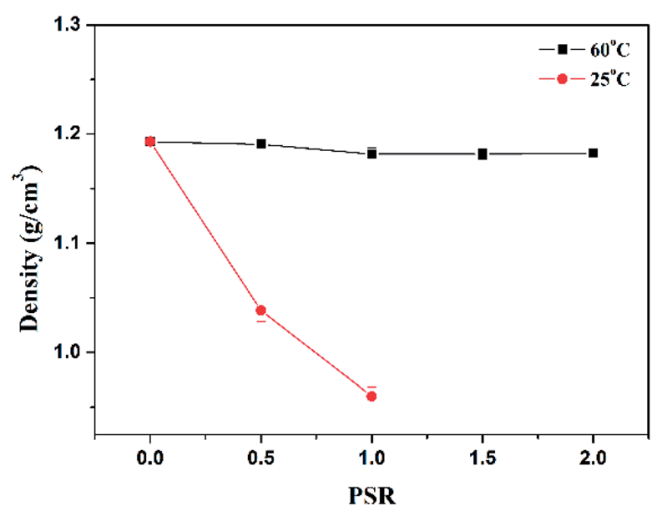

Fig. 7 The effects of PSR on the density of the PLA/PEBA blend before and after a uniaxial pre-stretching process at different temperatures. well-organized molecular chains could also hinder the further extension of the cracks, resulting in an increase in the strength at the yielding and break point as well as the tensile modulus of the PLA/PEBA blend. However, at $25{ }^{\circ} \mathrm{C}$, the orientation and strain-induced crystals were also formed during the prestretching process, but these occurred alongside a pronounced phase-separation as well as the formation of crack and pore defects in both the PLA and PEBA phases, which were almost invisible at $60{ }^{\circ} \mathrm{C}$. Moreover, this result can be further confirmed by the apparent density analysis, as presented in Fig. 7. It turns out that the apparent density of the psPLA/PEBA blend pre-stretched at $25{ }^{\circ} \mathrm{C}$ sharply decreased on increasing the PSR, whereas the apparent density of the corresponding samples at $T_{\mathrm{ps}}=60^{\circ} \mathrm{C}$ showed no distinct change and were thus independent of the PSR. Consequently, the phaseseparation as well as the crack and pore defects formed in the cold-drawn sample hindered the improvement of the tensile strength and the modulus. Accordingly, a higher tensile strength and modulus as well as elongation at break for the prestretched blend were obtained at $T_{\mathrm{ps}}=60^{\circ} \mathrm{C}$ compared to those at $T_{\mathrm{ps}}=25^{\circ} \mathrm{C}$.

\section{Conclusions}

With the addition of PEBA to the PLA matrix, the toughness of the undrawn PLA/PEBA blend showed a significant improvement, but alongside with a sacrifice in the tensile strength and modulus. Highly oriented PLA/PEBA blends were prepared by a uniaxial pre-stretching process at $60{ }^{\circ} \mathrm{C}$ and $25^{\circ} \mathrm{C}$. When the PLA/PEBA blend was pre-stretched at $60{ }^{\circ} \mathrm{C}$, the strength at yielding and break, as well as the modulus of the drawn blend, were significantly improved on increasing the PSR, with their maximum values amounting to $68.8 \mathrm{MPa}, 100 \mathrm{MPa}$, and $2370 \mathrm{MPa}$, respectively, whereas the elongation at break still maintained a high value (60\%), suggesting that the PEBA still had an excellent toughening effect for PLA under the uniaxial pre-stretching process. The SEM and WAXD analyses revealed that the orientation developed and the strain-induced crystallization proceeded after the pre-stretching process at both $60^{\circ} \mathrm{C}$ and $25{ }^{\circ} \mathrm{C}$. However, the phase-separation as well as some cracks and pores appeared in both the PEBA and PLA phases at $T_{\mathrm{ps}}=25{ }^{\circ} \mathrm{C}$, which impeded the improvement of the tensile 
strength and modulus for PLA. With the increase in PSR, the glass transition shifted to higher temperature, whereas the coldcrystallization peak moved to a lower temperature and its peak area became smaller; thus, the crystallinity of the drawn blend increased. These results indicate that the orientation and strain-induced crystallization grew while pre-stretching, which suggests that these were the key aspects to strengthen and stiffen the PLA matrix. Consequently, pre-stretching the toughened PLA blend can be useful for fabricating the appropriate materials of specific applications, such as films for the preservation of agricultural products and woven bags.

\section{Acknowledgements}

This work was funded by the National Natural Science Foundation of China (51503204, 51273201).

\section{Notes and references}

1 R. E. Drumright, P. R. Gruber and D. E. Henton, Adv. Mater., 2000, 12, 1841-1846.

2 K. J. Zhu, X. Z. Lin and S. L. Yang, J. Appl. Polym. Sci., 1990, 39, 1-9.

3 L. Fambri, A. Pegoretti, R. Fenner, S. D. Incardona and C. Migliaresi, Polymer, 1997, 38, 79-85.

4 S. Van Vlierberghe, P. Dubruel and E. Schacht, Biomacromolecules, 2011, 12, 1387-1408.

5 R. Auras, B. Harte and S. Selke, Macromol. Biosci., 2004, 4, 835-864.

6 R. G. Sinclair, J. Macromol. Sci., Part A: Pure Appl.Chem., 1996, 33, 585-597.

7 L. Xie, H. Xu, B. Niu, X. Ji, J. Chen, Z. M. Li, B. S. Hsiao and G. J. Zhong, Biomacromolecules, 2014, 15, 4054-4064.

8 S. Ishida, R. Nagasaki, K. Chino, T. Dong and Y. Inoue, J. Appl. Polym. Sci., 2009, 113, 558-566.

9 M. Harada, T. Ohya, K. Iida, H. Hayashi, K. Hirano and H. Fukuda, J. Appl. Polym. Sci., 2007, 106, 1813-1820.

10 T. Takayama and M. Todo, J. Mater. Sci., 2006, 41, 49894992.

11 L. Jiang, M. P. Wolcott and J. W. Zhang, Biomacromolecules, 2006, 7, 199-207.

12 L. J. Han, C. Y. Han and L. S. Dong, Polym. Compos., 2013, 34, 122-130.

13 A. Suzuki and A. Endo, Polymer, 1997, 38, 3085-3089.

14 X. X. Hou, X. P. Yang, F. Zhang, S. Z. Wu and E. Waclawik, Int. J. Mod. Phys. B, 2008, 22, 5913-5918.

15 A. Suzuki and T. Kohno, J. Appl. Polym. Sci., 2000, 75, 15691576.
16 S. Z. Wu, F. Zhang, Y. H. Yu, P. Li, X. P. Yang, J. G. Lu and S. Ryu, Compos. Interfaces, 2008, 15, 671-677.

17 Z. Y. Song, X. X. Hou, L. Q. Zhang and S. Z. Wu, Materials, 2011, 4, 621-632.

18 J. C. Velazquez-Infante, J. Gamez-Perez, E. A. FrancoUrquiza, O. O. Santana, F. Carrasco and M. L. Maspoch, J. Appl. Polym. Sci., 2013, 127, 2661-2669.

19 J.-H. Wu, M.-S. Yen, C.-P. Wu, C.-H. Li and M. C. Kuo, J. Polym. Environ., 2012, 21, 303-311.

20 P. Jariyasakoolroj, K. Tashiro, H. Wang, H. Yamamoto, W. Chinsirikul, N. Kerddonfag and S. Chirachanchai, Polymer, 2015, 68, 234-245.

21 F. Feng, X. Zhao and L. Ye, J. Macromol. Sci., Part B: Phys., 2011, 50, 1500-1507.

22 X. Zhao, L. Ye, P. Coates, F. Caton-Rose and M. Martyn, Polym. Adv. Technol., 2013, 24, 853-860.

23 J. P. Sheth, J. N. Xu and G. L. Wilkes, Polymer, 2003, 44, 743756.

24 V. Barbi, S. S. Funari, R. Gehrke, N. Scharnagl and N. Stribeck, Macromolecules, 2003, 36, 749-758.

25 L. J. Han, C. Y. Han and L. S. Dong, Polym. Int., 2013, 62, 295303.

26 G. Stoclet, R. Seguela, J. M. Lefebvre and C. Rochas, Macromolecules, 2010, 43, 7228-7237.

27 Y. Wang, M. Li, K. Wang, C. Shao, Q. Li and C. Shen, Soft Matter, 2014, 10, 1512-1518.

28 G. Stoclet, R. Seguela, J. M. Lefebvre, S. Elkoun and C. Vanmansart, Macromolecules, 2010, 43, 1488-1498.

29 Y. G. Galen, R. Hatfield, W. E. Killinger, R. A. Andrejak and P. M. Roubicek, Macromolecures, 1993, 26, 6350-6353.

30 Y. Wang, H. Zhang, M. Li, W. Cao, C. Liu and C. Shen, Polym. Test., 2015, 41, 163-171.

31 H. P. Zhang, J. Niemczura, G. Dennis, K. Ravi-Chandar and M. Marder, Phys. Rev. Lett., 2009, 102, 245503.

32 L. Yu, H. Liu, F. Xie, L. Chen and X. Li, Polym. Eng. Sci., 2008, 48, 634-641.

33 J. R. Sarasua, R. E. Prud'homme, M. Wisniewski, A. L. Borgne and N. Spassky, Macromolecules, 1998, 31, 3895-3905.

34 S. Huang, H. Li, S. Jiang, X. Chen and L. An, Polymer, 2011, 52, 3478-3487.

35 T. Kawai, N. Rahman, G. Matsuba, K. Nishida, T. Kanaya, M. Nakano, O. H. J. Kawada, A. Usuki, N. Honma, K. Nakajima and M. Matsuda, Macromolecules, 2007, 40, 9463-9469.

36 Y. Yin, X. Zhang, Y. Song, S. de Vos, R. Wang, C. A. P. Joziasse, G. Liu and D. Wang, Polymer, 2015, 65, 223-232. 